\title{
Resistin and Cardiovascular Disease
}

Elena Parreño ${ }^{1^{*}}$, Clara Palomares ${ }^{2}$, Mariana Martínez ${ }^{2}$, Raúl Ballester ${ }^{3}$, Luz Martínez ${ }^{4}$ and Aisa Fornovi ${ }^{5}$

${ }^{1}$ Department of Cardiology, Hospital de la Vega Lorenzo Guirao, Cieza, Spain

${ }^{2}$ Department of Cardiology, Hospital Comarcal del Noroeste, Caravaca de la Cruz, Spain

${ }^{3}$ Department of Cardiology, Hospital Virgen del Castillo, Yecla, Spain

${ }^{4}$ Department of Cardiology, Hospital Rafael Méndez, Spain

${ }^{5}$ Department of Cardiology, Hospital Vega Baja, Orhiuela, Spain

"Corresponding author: Elena Parreño, Department of Cardiology, Hospital de la Vega Lorenzo Guirao, Cieza, Spain, Tel: 0034626818642; E-mail: elenapcnet@yahoo.es

Received: June 08, 2018; Accepted: July 27, 2018; Published: July 30, 2018

Copyright: (c) 2018 Parreno E, et al. This is an open-access article distributed under the terms of the creative commons attribution license, which permits unrestricted use, distribution, and reproduction in any medium, provided the original author and source are credited.

\begin{abstract}
Different studies have suggested the involvement of resistin in the pathogenesis of cardiovascular diseases, including hypertension, coronary artery disease, heart failure and cerebrovascular disease. Different articles were retrieved by searching the following databases: PubMed, Embase, Ovid Medline. Based on our results, we conclude that serum resistin concentration is involved in the pathogenesis of arteriosclerosis. In addition, serum resistin levels are increased in patients with hypertension, coronary heart disease and cerebrovascular disease, and are related to the development and worsening of heart failure.
\end{abstract}

Keywords: Resistin; Cardiovascular disease

\section{Introduction}

Resistin is a hormone composed of 108 amino acids, with a crystalloid structure, belonging to the family of cysteine-rich proteins known as resistin-like molecules (RELMs), characterized by a single site comprising 10-11 cysteine groups [1-3]. Adipocytes are the main source of resistin in rodents [1,2], though in humans the main sources are monocytes and macrophages-a fact that suggests a link between resistin and inflammation. Different studies have reported high plasma resistin levels in patients with cardiovascular disease that are not correlated to the presence of arterial hypertension (AHT), diabetes mellitus (DM), smoking or body mass index (BMI), but which are related to $\mathrm{C}$-reactive protein (CRP) concentration. This suggests that resistin is associated with cardiovascular disease through inflammatory pathways $[4,5]$. Other studies postulate that inflammation does not seem to be the only factor involved in this association. The present review discusses the role of resistin in cardiovascular disease.

\section{Literature Review}

\section{Resistin, arteriosclerosis and arterial hypertension}

Resistin appears to be implicated in the pathogenesis of arteriosclerosis, due to its association with inflammatory processes and its role in endothelial dysfunction. According to different in vitro studies, resistin promotes the endothelial cell release of endothelin 1 (ET-1), vascular cell adhesion protein 1 (VCAM-1), intercellular adhesion molecule 1 (ICAM-1), monocyte chemoattractant protein-1 (MCP-1) and pentraxin 3 (PTX3) and reduces the expression of factor 3 associated with the tumor necrosis factor (TNF) receptor [6,7]. Resistin also activates human aortic smooth muscle through extracellular pathways related to protein kinase activated by mitogen p42/44 and the protein kinase B signaling pathways [8]. Furthermore, resistin promotes lipid accumulation in macrophages, which leads to the formation of foam cells through action upon the phagocyte class $\mathrm{A}$ receptors, cluster of differentiation 36 (CD36), and adenosine triphosphate binding cassette transporter A1 in macrophages [9]. Resistin can also produce endothelial dysfunction through oxidative stress and the reduction of endothelial nitric oxide synthase $[10,11]$. New data show that protein kinase C-epsilon (PKCe) and toll-like receptor 4 (TLR4) synergically promote the activation of nuclear factor kappa-light chain-enhancer of activated B cells (NF-kB) in the regulation of inflammation mediated by resistin in human macrophages [12]. Raghuraman et al. showed that vascular smooth muscle cell dysfunction associated with resistin and hyperplasia of the intimal layer is related to the activation of NADPH oxidase (Nox) dependent on PKCe and the generation of reactive oxygen species (ROS). The authors suggest that the PKCe-Nox pathway could constitute a possible new target in the treatment of atherosclerotic complications related to resistin [13] (Figure 1).

In humans, resistin is mainly expressed by inflammatory cells such as macrophages [14], and activation of the inflammatory cascade induces resistin expression [15]. Different studies have described an association between plasma resistin levels and CRP concentration [16-18]. However, other studies have reported elevated resistin levels in relation to coronary artery calcification, independently of the CRP concentrations [19] thus suggesting that inflammation is not the only mediating factor in this association. In atherosclerotic aneurysms, the infiltrating macrophages secrete resistin, which in turn induces endothelial cell production of PAI-1 and ET-1, as well as vascular smooth muscle cell migration [20]. Burnett et al. showed that both mRNA encoding for resistin and the protein itself are present in aortic atherosclerotic lesions in rats with apolipoprotein E deficiency, and that the resistin levels are elevated in patients with premature coronary disease compared with patients presenting angiographically normal coronary arteries [21]. 


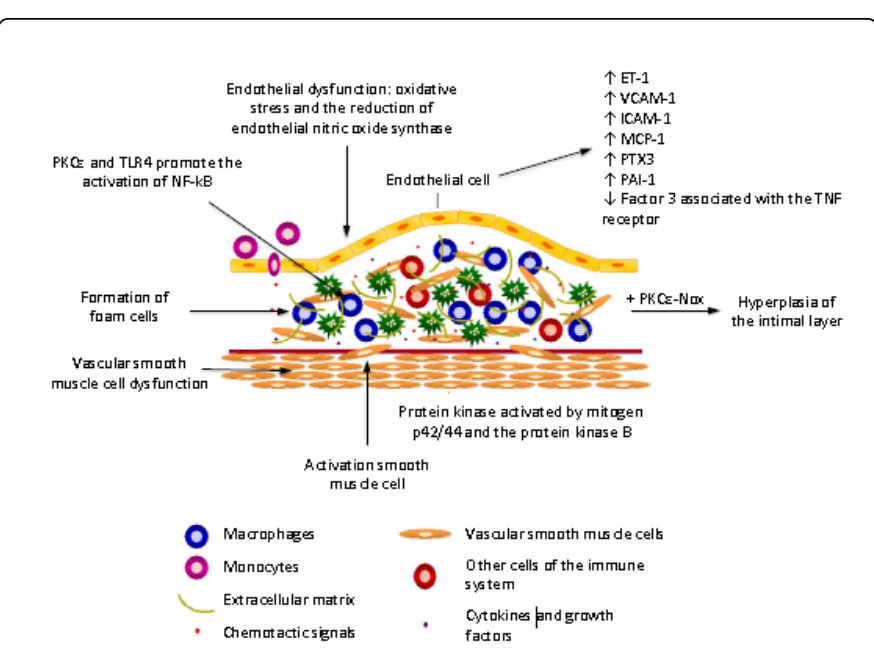

Figure 1: Implication of resistin in the pathogenesis of arteriosclerosis.

In terms of clinical application, elevated resistin levels are associated with an increased risk of AHT in non-diabetic women [22]. Certain resistin gene polymorphisms are associated with elevated systolic blood pressure [23]. Resistin concentration is increased not only in diabetic individuals [24] but also in patients with pre-hypertension [25]. Recent investigations have related resistin to AHT [26]. Fourteen case-control studies comprising 718 hypertensive individuals and 645 controls with normal blood pressure have been analyzed in a metaanalysis published by Zhang et al. [27]. A significant association was found between serum resistin concentration and hypertension, particularly in Asian and Hispanic populations, and in diabetic subjects.

\section{Resistin and coronary artery disease}

Many studies have found elevated resistin concentration to be associated with a high risk of coronary disease [28,29]. Resistin levels are particularly high in patients with coronary disease and diminished insulin sensitivity [30] and diabetes mellitus [31]. Individuals with acute coronary syndrome (ACS) have higher resistin levels than patients with stable angina, and resistin concentration is correlated to the number of coronary arteries with stenosis $>50 \%$ [32-34]. In another study, patients with ACS showed elevated resistin levels, and only in this group was resistin seen to be correlated to CRP concentration. A proportional increase in resistin is observed with the number of stenotic coronary arteries, and the hormone has been seen to be significantly predictive of ACS [35]. Resistin is also predictive of coronary calcification and metabolic syndrome [36] and has been independently associated with arterial stiffness in the Baltimore Longitudinal Study of Aging [37] (Figure 2).

\section{Resistin and heart failure}

Although the association between human resistin and heart failure has not been as widely studied as the relationship between resistin and coronary disease, there is growing evidence that resistin elevation is associated with the development and worsening of heart failure [38]. The serum resistin levels are higher in patients with heart failure and increase with progressing New York Heart Association (NYHA) functional class. Moreover, the incidence of cardiac events is greater in patients with high resistin levels compared with normal levels in the context of heart failure [39].

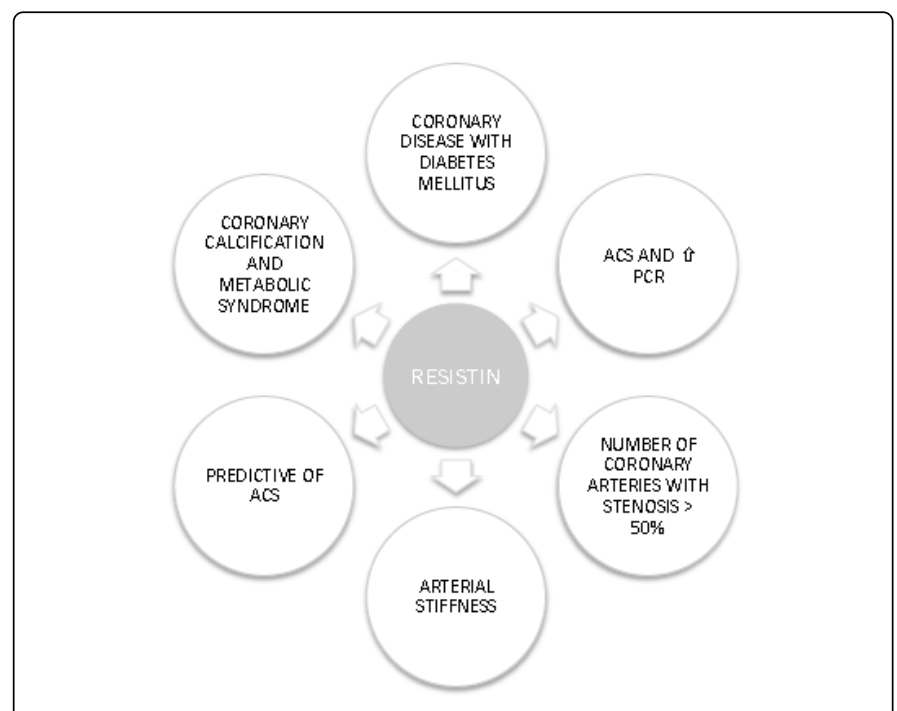

Figure 2: Association of resistin with coronary artery disease.

The Framingham Offspring Study suggests that the resistin levels are inversely correlated to left ventricular fractional shortening - a marker of left ventricular systolic function [40] and that resistin is an independent predictor of heart failure in the same cohort [41]. A total of 2902 elderly people with heart failure enrolled in the Health, Aging and Body Composition Study, involving a follow-up period of 9 years, showed an increased risk of hospital admission due to heart failure in the presence of increased resistin levels, after controlling for known risk factors [42]. The Heart and Soul Study of United States veterans with known stable coronary disease has found that those individuals with resistin levels in the upper quartile are at an increased risk of heart failure and death after controlling for age, gender and race [43] (Figure 3).

\section{Resistin and cerebrovascular disease}

The PRIME study, a large prospective trial involving 9771 patients followed-up on for 10 years, has shown elevated resistin levels to be significantly associated with the presence of ischemic stroke [44]. This association had not been previously identified in a large cohort of middle-aged individuals. However, elevated resistin is associated with an increased risk of myocardial infarction [45]. The results of the Women's Health Initiative Observational Study, published in early 2011 , indicate that resistin, but not adiponectin or leptin, is strongly predictive of ischemic stroke in postmenopausal women. Resistin is associated with an increased risk of ischemic stroke, though curiously this correlation decreases after controlling for CRP (though statistical significance is maintained), thus suggesting that this association can be explained only in part by CRP concentration [46]. In another cohort of patients with multiple-vessel coronary disease followed-up on for one year, resistin but not adiponectin was identified as an independent predictor of cardiac and brain events such as cerebrovascular accidents [47]. 


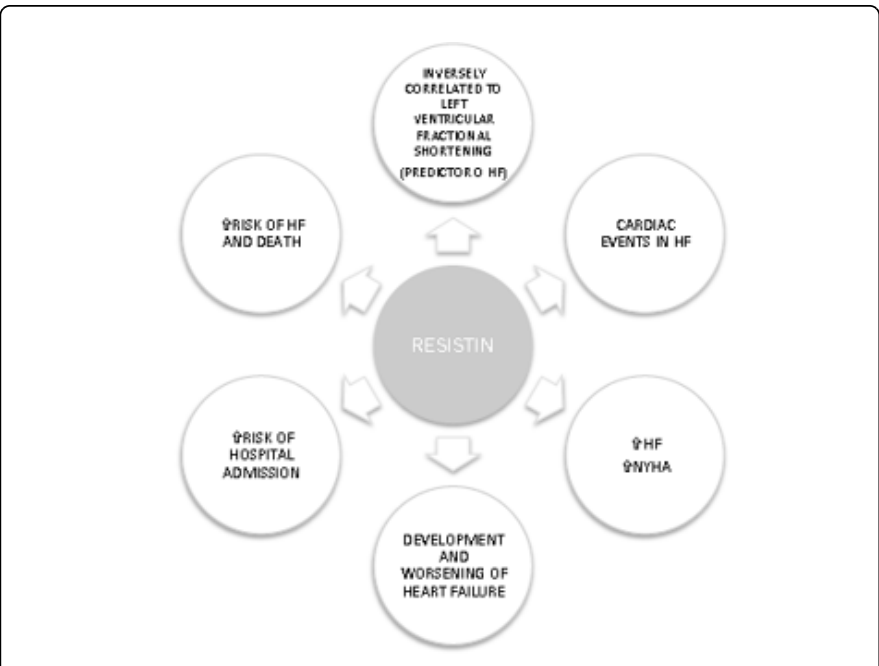

Figure 3: Association of resistin with heart failure.

Furthermore, following an ischemic cerebrovascular accident, the resistin levels were found to be predictive of the risk of death or neurological disability over 5 years [48]. A recent meta-analysis of 10 studies involving 1829 acute cerebral infarction patients and 1557 healthy controls has recorded comparatively higher resistin levels among the former. An analysis by subgroups revealed a significant association between resistin concentration and acute cerebral infarction in Asians but not in Caucasians [49] (Figure 4).

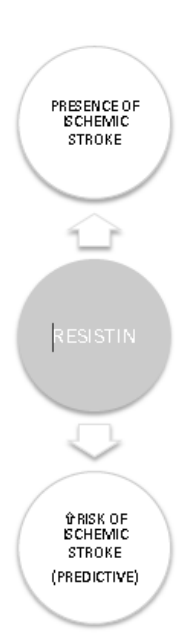

Figure 4: Association of resistin with cerebrovascular disease.

\section{Conclusion}

There is evidence of the possible role of resistin in the pathogenesis of arteriosclerosis, due to its implication in inflammatory processes and endothelial dysfunction. Atherosclerotic lesions contain both mRNA encoding for resistin and the protein itself; the infiltrating macrophages secrete resistin, and the latter induces the release of different molecules implicated in endothelial dysfunction, as well as the activation of smooth muscle cells. Resistin also produces endothelial dysfunction through oxidative stress. In routine clinical practice, there is growing evidence that elevated serum resistin levels are associated with AHT, coronary disease, the development and worsening of heart failure, and the presence of ischemic stroke. Nevertheless, many details still need to be clarified in order to confirm the role and implication of resistin in the pathogenesis and treatment of different cardiovascular diseases.

\section{References}

1. Steppan CM, Bailey ST, Bhat S, Brown EJ, Banerjee RR, et al. (2001) The hormone resistin links obesity to diabetes. Nature 409: 307-312.

2. Kim KH, Lee K, Moon YS, Sul HS (2001) A cysteine-rich adipose tissuespecific secretory factor inhibits adipocyte differentiation. J Biol Chem 276: 11252-11256.

3. Holcomb IN, Kabakoff RC, Chan B, Baker TW, Gurney A, et al. (2000) FIZZ1, a novel cysteine-rich secreted protein associated with pulmonary inflammation, defines a new gene family. EMBO J 19: 4046-4055.

4. Ohmori R, Momiyama Y, Kato R, Taniguchi H, Ogura M, et al. (2005) Associations between serum resistin levels and insulin resistance, inflammation, and coronary artery disease. J Am Coll Cardiol 46: 379-380.

5. Pischon T, Bamberger CM, Kratzsch J, Zyriax BC, Algenstaedt P, et al. (2005) Association of plasma resistin levels with coronary heart disease in women. Obes Res 13: 1764-1771.

6. Verma S, Li SH, Wang CH, Fedak PW, Li RK, et al. (2003) Resistin promotes endothelial cell activation: Further evidence of adipokineendothelial interaction. Circulation 108: 736-740.

7. Kawanami D, Maemura K, Takeda N, Harada T, Nojiri T, et al. (2004) Direct reciprocal effects of resistin and adiponectin on vascular endothelial cells: A new insight into adipocytokine-endothelial cell interactions. Biochem Biophys Res Commun 314: 415-419.

8. Calabro P, Samudio I, Willerson JT, Yeh ET (2004) Resistin promotes smooth muscle cell proliferation through activation of extracellular signal-regulated kinase 1/2 and phosphatidylinositol 3-kinase pathways. Circulation 110: 3335-3340.

9. Lee TS, Lin CY, Tsai JY, Wu YL, Su KH, et al. (2009) Resistin increases lipid accumulation by affecting class A scavenger receptor, CD36 and ATP-binding cassette transporter-A1 in macrophages. Life Sci 84: 97-104.

10. Kougias P, Chai H, Lin PH, Lumsden AB, Yao QZ, et al. (2005) Adipocyte-derived cytokine resistin causes endothelial dysfunction of porcine coronary arteries. J Vasc Surg 41: 691-698.

11. Chen C, Jiang J, Lü JM, Chai H, Wang X, et al. (2010) Resistin decreases expression of endothelial nitric oxide synthase through oxidative stress in human coronary artery endothelial cells. Am J Physiol Heart Circ Physiol 299: H193-H201.

12. Zuniga MC, Raghuraman G, Hitchner E, Weyand C, Robinson W, et al. (2017) PKC-epsilon and TLR4 synergistically regulate resistin-mediated inflammation in human macrophages. Atherosclerosis 259: 51-59.

13. Raghuraman G, Zuniga MC, Yuan H, Zhou W (2016) PKC mediates resistin-induced NADPH oxidase activation and inflammation leading to smooth muscle cell dysfunction and intimal hyperplasia. Atherosclerosis 253: 29-37.

14. Patel L, Buckels AC, Kinghorn IJ, Murdock PR, Holbrook JD, et al. (2003) Resistin is expressed in human macrophages and directly regulated by PPAR gamma activators. Biochem Biophys Res Commun 300: 472-476.

15. Lehrke M, Reilly MP, Millington SC, Iqbal N, Rader DJ, et al. (2004) An inflammatory cascade leading to hyperresistinemia in humans. PLoS Med 1: e45.

16. Bo S, Gambino R, Pagani A, Guidi S, Gentile L, et al. (2005) Relationships between human serum resistin, inflammatory markers and insulin resistance. Int J Obes Relat Metab Disord 29: 1315-1320.

17. Shetty GK, Economides PA, Horton ES, MAntzoros CS, Veves A (2004) Circulating adiponectin and resistin levels in relation to metabolic 
factors, inflammatory markers, and vascular reactivity in diabetic patients and subjects at risk for diabetes. Diabetes Care 27: 2450-2457.

18. Kunnari A, Ukkola O, Paivansalo M, Kesaniemi YA (2006) High plasma resistin level is associated with enhanced highly sensitive C-reactive protein and leukocytes. J Clin Endocrinol Metab 91: 2755-2760.

19. Reilly MP, Lehrke M, Wolfe ML, Rohatgi A, Lazar MA, et al. (2005) Resistin is an inflammatory marker of atherosclerosis in humans. Circulation 111: 932-939.

20. Jung HS, Park KH, Cho YM, Chung SS, Cho HJ, et al. (2006) Resistin is secreted from macrophages in atheromas and promotes atherosclerosis. Cardiovasc Res 69: 76-85.

21. Burnett MS, Lee CW, Kinnaird TD, Stabile E, Durrani S, et al. (2005) The potential role of resistin in atherogenesis. Atherosclerosis 182: 241-248.

22. Zhang L, Curhan GC, Forman JP (2010) Plasma resistin levels associate with risk for hypertension among nondiabetic women. J Am Soc Nephrol 21: 1185-1191.

23. Conneely KN, Silander K, Scott LJ, Mohlke KL, Lazaridis KN, et al. (2004) Variation in the resistin gene is associated with obesity and insulin-related phenotypes in Finnish subjects. Diabetologia 47: 1782-1788.

24. Osawa H, Ochi M, Tabara Y, Kato K, Yamauchi J, et al. (2008) Serum resistin is positively correlated with the accumulation of metabolic syndrome factors in type 2 diabetes. Clin Endocrinol (Oxf) 69: 74-80.

25. Papadopoulos DP, Makris TK, Krespi PG, Poulakou M, Stavroulakis G, et al. (2005) Adiponectin and resistin plasma levels in healthy individuals with prehypertension. J Clin Hypertens (Greenwich) 7: 729-733.

26. Park HK, Kwak MK, Kim HJ, Ahima RS (2017) Linking resistin, inflammation, and cardiometabolic diseases. Korean J Intern Med 32: 239-247.

27. Zhang Y, Li Y, Yu L, Zhou L (2017) Association between serum resistin concentration and hypertension: A systematic review and meta-analysis. Oncotarget 8: 41529-41537.

28. Hussain S, Bibi S, Javed Q (2011) Heritability of genetic variants of resistin gene in patients with coronary artery disease: A family-based study. Clin Biochem 44: 618-622.

29. Baker JF, Morales M, Qatanani M, Cucchiara A, Nackos E, et al. (2011) Resistin levels in lupus and associations with disease-specific measures, insulin resistance, and coronary calcification. J Rheumatol 38: 2369-2375.

30. Krysiak R, Sierant M, Marek B, Okopien B (2011) The effect of perindopril and enalapril on plasma resistin levels in normotensive patients with coronary heart disease. Endokrynol Pol 61: 683-690.

31. Korah TE, Ibrahim HH, Badr EA, Elshafie MK (2011) Serum resistin in acute myocardial infarction patients with and without diabetes mellitus. Postgrad Med J 87: 463-467.

32. Wang H, Chen DY, Cao J (2009) High serum resistin level may be an indicator of the severity of coronary disease in acute coronary syndrome. Chin Med Sci J 24: 161-166.

33. Hu WL, Qiao SB, Hou Q, Yuan JS (2007) Plasma resistin is increased in patients with unstable angina. Chin Med J 120: 871-875.

34. Chu S, Ding W, Li K, Pang Y, Tang C (2008) Plasma resistin associated with myocardium injury in patients with acute coronary syndrome. Circ J 72: 1249-1253.
35. Wang H, Chen DY, Cao J, He ZY, Zhu BP, et al. (2009) High serum resistin level may be an indicator of the severity of coronary disease in acute coronary syndrome. Chin Med Sci J 24: 161-166.

36. Meilly MP, Lehrke M, Wolfe ML, Rohatgi A, Lazar MA, et al. (2005) Resistin is an inflammatory marker of atherosclerosis in humans. Circulation 111: 932-939.

37. Windham BG, Griswold ME, Farasat SM, Ling SM, Carlson O, et al (2010) Influence of leptin, adiponectin, and resistin on the association between ab-dominal adiposity and arterial stiffness. Am J Hypertens 23: 501-507.

38. Schwartz DR, Lazar MA (2011) Human resistin: Found in translation from mouse to man. Trends Endocrinol Metab 22: 259-265.

39. Takeishi Y, Niizeki T, Arimoto T, Nozaki N, Hirono O, et al. (2007) Serum resistin is associated with high risk in patients with congestive heart failure: A novel link between metabolic signals and heart failure. Circ J 71: 460-464.

40. McManus DD, Lyass A, Ingelsson E, Massaro JM, Meigs JB, et al. (2012) Relations of circulating resistin and adiponectin and cardiac structure and function: The framingham offspring study. Obesity (Silver Spring) 20: 1882-1886.

41. Frankel DS, Vesan RS, D’Agostino RB, Benjamin EJ, Levy D, et al. (2009) Resistin, adiponectin, and risk of heart failure: The framingham offspring study. J Am Coll Cardiol 53: 754-762.

42. Butler J, Kalogeropoulos A, Georgiopoulou V, De Rekeneire N, Rodondi N, et al. (2009) Serum resistin concentrations and risk of new onset heart failure in older persons: The health, aging, and body composition (Health ABC) study. Arterioscler Thromb Vasc Biol 29: 1144-1149.

43. Zhang MH, Na B, Schiller NB, Whooley MA (2011) Association of resistin with heart failure and mortality in patients with stable coronary heart disease: Data from the heart and soul study. J Card Fail 17: 24-30.

44. Prugger C, Luc G, Haas B, Morange PE, Ferrieres J, et al. (2013) Multiple biomarkers for the prediction of ischemic stroke: The prime study. Arterioscler Thromb Vasc Biol 33: 659-666.

45. Weikert C, Westphal S, Berger K, Dierkes J, Möhlig M, et al. (2008) Plasma resistin levels and risk of myocardial infarction and ischemic stroke. J Clin Endocrinol Metab 93: 2647-2653.

46. Rajpathak SN, Kaplan RC, Wassertheil-Smoller S, Cushman M, Rohan TE, et al. (2011) Resistin, but not adiponectin and leptin, is associated with the risk of ischemic stroke among postmenopausal women: Results from the Women's Health Initiative. Stroke 42: 1813-1820.

47. Krecki R, Krzeminska-Pakula M, Peruga JZ, Szczesniak P, Lipiec P, et al. (2011) Elevated resistin opposed to adiponectin or angiogenin plasma levels as a strong, independent predictive factor for the occurrence of major adverse cardiac and cerebrovascular events in patients with stable multivessel coronary artery disease over 1-year follow-up. Med Sci Monit 17: 26-32.

48. Efstathiou SP, Tsiakou AG, Tsioulos DI, Panagiotou TN, Pefanis AV, et al. (2007) Prognostic significance of plasma resistin levels in patients with atherothrombotic ischemic stroke. Clin Chim Acta 378: 78-85.

49. Dong XL, Xu SJ, Zhang L, Zhang XQ, Liu T, et al. (2017) Serum resistin levels may contribute to an increased risk of acute cerebral infarction. Mol Neurobiol 54: 1919-1926. 